\title{
Editorial
}

\section{Editorial: Estimating Survivorship in the Face of Competing Risks}

\author{
M. Daniel Wongworawat MD, Matthew B. Dobbs MD, Mark C. Gebhardt MD, \\ Terence J. Gioe MD, Seth S. Leopold MD, Paul A. Manner MD, \\ Clare M. Rimnac PhD, Raphaël Porcher PhD
}

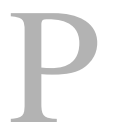
atients ask two main questions when considering an orthopaedic reconstruction: (1) Does it work? And (2) will it last? We have devoted a great deal of space on the Editorial and Spotlight pages of Clinical Orthopaedics and Related

The authors certify that they or any members of their immediate families, have no commercial associations (eg, consultancies, stock ownership, equity interest, patent/ licensing arrangements, etc) that might pose a conflict of interest in connection with the submitted article.

All ICMJE Conflict of Interest Forms for authors and Clinical Orthopaedics and Related Research ${ }^{\circledR}$ editors and board members are on file with the publication and can be viewed on request.

The opinions expressed are those of the writers, and do not reflect the opinion or policy of $C O R R^{\mathbb{R}}$ or the Association of Bone and Joint Surgeons ${ }^{\mathbb{R}}$.

\section{D. Wongworawat MD}

Department of Orthopaedic Surgery, Loma Linda University School of

Medicine, Loma Linda, CA, USA

\section{B. Dobbs MD}

Department of Orthopaedic Surgery, Washington University School of Medicine in St. Louis, St. Louis, MO, USA

M. C. Gebhardt MD

Orthopaedic Surgery, Beth Israel Deaconess Medical Center, Boston, MA, USA
Research $^{\circledR}$ to the question of efficacy, and we have considered its importance in many areas.

- How big of a difference is a patient likely to detect [5]?

- Have we overlooked women as we design laboratory and clinical research studies [7]?

- And what is the difference between efficacy and safety[6]?

By comparison, the question of durability may have gotten short shrift. For decades now, our specialty—and our Journal-have relied on the nowubiquitous Kaplan-Meier method of estimating survivorship [4]. This approach is superior to crude survivorship calculations since the Kaplan-Meier estimator adjusts for

\section{T. J. Gioe MD}

Minneapolis Veterans Affairs Medical

Center, Minneapolis, MN, USA

\section{S. S. Leopold MD (ه)}

Clinical Orthopaedics and Related

Research, Philadelphia, PA 19103, USA

e-mail: sleopold@clinorthop.org

P. A. Manner MD

Department of Orthopaedics and Sports

Medicine, University of Washington

School of Medicine, Seattle, WA, USA patients whose status cannot be determined because they have not failed as of the end of the study, or because they have been lost to followup. Two generations (or more) of orthopaedic surgeons have grown accustomed to using the familiar-looking survivorship curves we find in intermediate- and long-term followup papers about our reconstructions. That just about covers it, right?

Maybe not. The Kaplan-Meier approach is extremely effective for the purpose for which it was designed: Estimating survival, defined as the absence of death. In orthopaedic surgery, however, survivorship often refers to the absence of failure of a reconstruction. And here, the KaplanMeier method has shortcomings, particularly if some of the patients who

C. M. Rimnac $\mathrm{PhD}$

Case Western Reserve University, Cleveland, OH, USA

\section{R. Porcher PhD}

Center of Clinical Epidemiology, Hôpital Hôtel-Dieu, Paris, France 
Fig. 1A-F Kaplan-Meier (KM, black) and cumulative incidence $(\mathrm{Cl}$, gray) estimates of the probability of the occurrence of an event of interest over time are shown according to the total proportion of patients experiencing a competing event noted at the top of each graph (exponential independent latent failure times model). (A) $2 \%$

competing events (B) $5 \%$ competing events (C) $10 \%$ competing events (D) $20 \%$ competing events (E) 33\% competing events, and (F) $50 \%$ competing events. As the frequency of the competing event starts to exceed $10 \%$ and the followup duration goes beyond 10 years, the competing event results in substantial overestimation of the outcome of interest. Competing events $=$ The occurrence of events (such as death) that would preclude the later occurrence of an event of interest (such as implant revision). Probability of outcome $=$ The probability of the occurrence of an outcome of interest (such as implant revision), given the proportion of patients experiencing a competing event (such as death).
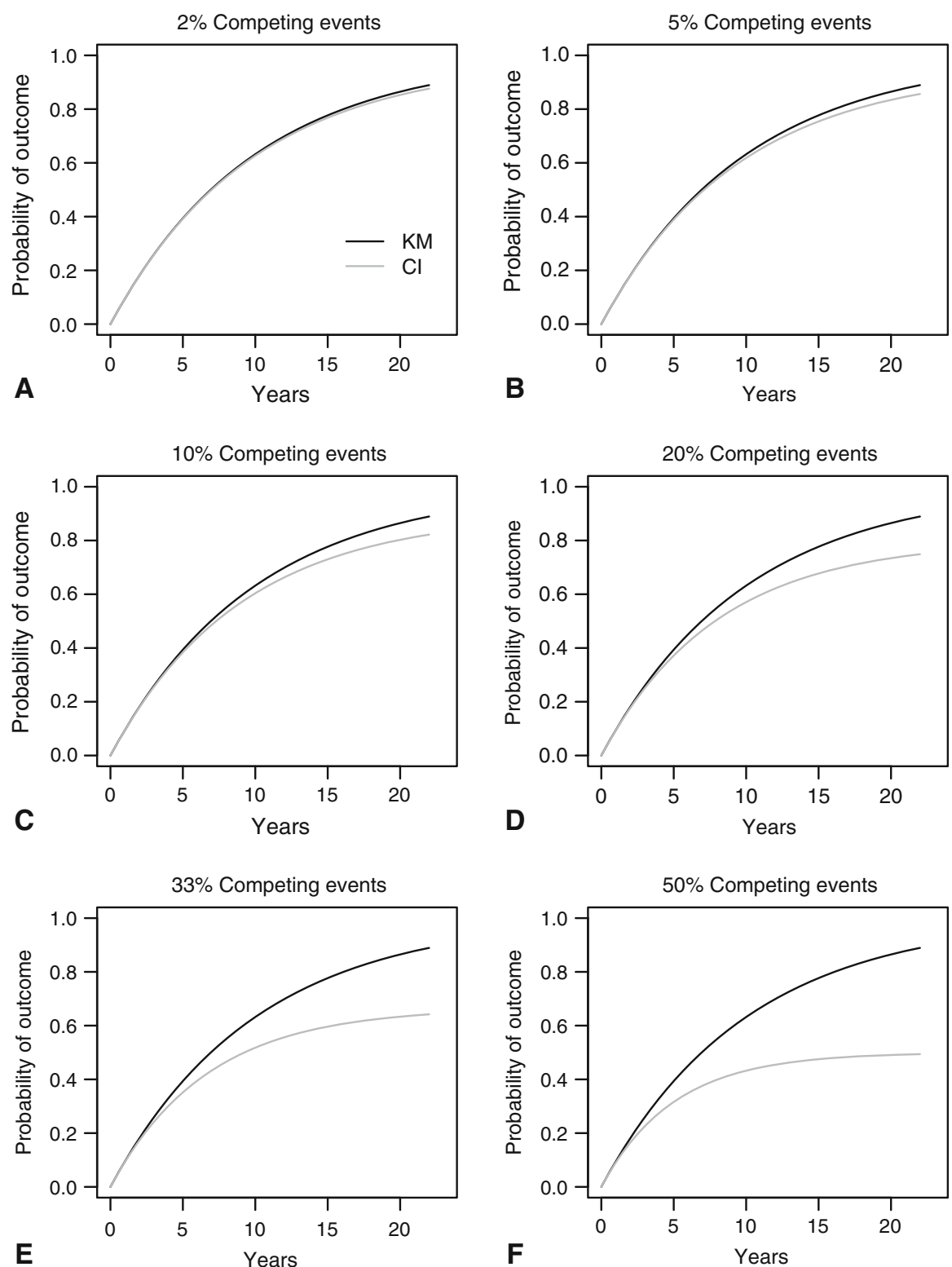
underwent surgical reconstruction die at some point during a study's followup period.

Imagine a paper on the durability of a particular arthroplasty design that followed patients for more than a decade. A large proportion of patients will enjoy continued use of the implant for the full study period and beyond, some will undergo revision surgery, others will be lost to followup (and so might get revised, but we do not know), and still others may die from causes unrelated to the reconstruction. Well-functioning and revised implants each represent obvious endpoints for analysis, and Kaplan-Meier statistics adjust the survivorship estimates to account for those others who are lost and may have been revised. But while a patient who is lost to followup may undergo revision, a patient who has died cannot. The presence of such competing events-defined as outcomes (such as death) that preclude the occurrence of the endpoint of interest (revision)-are not accounted for in Kaplan-Meier estimates.

In technical terms, the event of death is informative - a dead patient cannot later develop an implant failure. But Kaplan-Meier survivorship treats those lost to followup (and who may subsequently undergo revision) similarly to those who have died (and so cannot undergo revision). Because of this, the Kaplan-Meier approach will overestimate the likelihood of implant failure if a substantial proportion of a study's patients have died [1, 2, 8].

Better approaches exist for this scenario [1, 2, 8]. Competing-risk calculations (sometimes called competing-incidence analyses) take into account the combined probability of a patient experiencing implant failure (the event of interest) given that (s)he has survived thus far, without implant failure or death (the competing risk). If a substantial proportion of patients die during the followup period, then late failure becomes less likely, and the survivorship estimate is increased accordingly. Since death precludes a later implant failure, the competingrisk model accounts for the fact that we know that an individual has no chance of needing revision surgery after death.

The differences between KaplanMeier survivorship and a competingrisks estimate can be large [9], and some of the world's arthroplasty registries have begun to acknowledge this by employing a competing-risks approach in lieu of Kaplan-Meier statistics where appropriate [3]. But the differences are not always large. When is the issue of competing risk small enough to not matter? Imagine another hypothetical study, in which a population of 100 patients have undergone tumor surgery for limb salvage. During the period of followup, one patient underwent amputation following a motor vehicle accident. While amputation in this scenario indeed precludes tumor recurrence, it was a rare event, and the competing risk therefore was very low. Therefore, in that scenario, KaplanMeier survivorship would be a suitable analytical approach to use.

In those situations where the frequency of the competing event is greater than $10 \%$ to $20 \%$, and the followup duration starts to approach 10 years (Fig. 1A-F), Clinical Orthopaedics and Related Research ${ }^{\circledR}$ will begin asking authors to consider alternatives to Kaplan-Meier survivorship, such as a competing-risks analysis. Where those alternatives cannot be implemented, we will ask authors to address this issue thoughtfully in the discussion section as an important study limitation.

And we encourage readers to consider this issue carefully when reading studies where survivorship is an important outcome measure.

\section{References}

1. Biau DJ, Latouche A, Porcher R. Competing events influence estimated survival probability: when is KaplanMeier analysis appropriate? Clin Orthop Relat Res. 2007;462:229-233.

2. Gooley TA, Leisenring W, Crowley J, Storer BE. Estimation of failure probabilities in the presence of 
competing risks: new representations of old estimators. Stat Med. 1999;18: 695-706.

3. Jämsen E, Eskelinen A, Peltola M, Mäkelä K. High early failure rate after cementless hip replacement in the octogenarian. Clin Orthop Relat Res. 2014;472:2779-89.

4. Kaplan EL, Meier P. Nonparametric estimation from incomplete observations. J Am Stat Assoc. 1958;53:457-481.

5. Leopold SS. Editor's Spotlight/Take 5: Comparative responsiveness and minimal clinically important differences for idiopathic ulnar impaction syndrome. Clin Orthop Relat Res. 2013;471:1403-1405.

6. Leopold SS. When "safe and effective" becomes dangerous. Clin Orthop Relat Res. 2014;472:1999-2001.

7. Leopold SS, Beadling L, Dobbs MB, Gebhardt, MC, Lotke PA, Manner PA, Rimnac CM, Wongworawat MD. Editorial - fairness to all: Gender and sex in scientific reporting. Clin Orthop Relat Res. 2014;472:391-392.
8. Satagopan JM. Ben-Porat L, Berwick M, Robson M, Kutler D, Auerbach AD. A Note on competing risks in survival data analysis. $\mathrm{Br} J$ Cancer. 2004;91:1229-1235.

9. Schuh R, Kaider A, Windhager R, Funovics PT. Does competing risks analysis give useful information about endoprosthetic survival in extremity osteosarcoma. [Published online ahead of print May 28, 2014]. Clin Orthop Relat Res. DOI: 10.1007/s11999-0143703-x. 